\title{
Genetic Resistance of Pearl Millet Male-Sterile Lines to Diverse Indian Pathotypes of Sclerospora graminicola
}

\author{
R. P. Thakur, K. N. Rai, V. P. Rao, and A. S. Rao, Genetic Resources and Enhancement Program, International \\ Crops Research Institute for the Semi-Arid Tropics (ICRISAT), Patancheru 502 324, Andhra Pradesh, India
}

\begin{abstract}
Thakur, R. P., Rai, K. N., Rao, V. P., and Rao, A. S. 2001. Genetic resistance of pearl millet male-sterile lines to diverse Indian pathotypes of Sclerospora graminicola. Plant Dis. 85:621626.

Single-cross $\mathrm{F}_{1}$ hybrid cultivars based on cytoplasmic-nuclear male-sterility (CMS) system have contributed significantly to increasing productivity of pearl millet (Pennisetum glaucum). Genetic resistance to downy mildew (Sclerospora graminicola) in parental lines is critical for successful commercial cultivation of a hybrid cultivar. In this study, 46 genetically diverse male-sterile lines (A-lines), including 42 test A-lines, four control A-lines, a commercial hybrid, and a highly susceptible line, were evaluated in disease nurseries at four diverse locations in India and compared with pathotype isolates from the same locations under greenhouse environments. Variability in downy mildew incidence ( 0 to $100 \%)$ due to genetic differences among lines, among pathotypes, and that due to line $\times$ pathotype interaction were all highly significant $(P<0.001)$. In the field experiment, eight of the 42 test A-lines, including $841 \mathrm{~A}$ (control), that recorded $\leq 10 \%$ disease incidence, were identified as resistant compared with 84 to $100 \%$ incidence on the control susceptible line 7042S. Resistance in eight of these test A-lines (863A, ICMA 88004, -94333, -98222, -98111, -92777, and -96666) and 841A was confirmed against the four pathotypes in greenhouse experiments. Cluster analysis of downy mildew incidence data from field and greenhouse experiments, using the Euclidian distance, classified the 48 lines into four distinct groups with the above eight A-lines in the resistant group. These resistant A-lines would be useful in the development of $F_{1}$ hybrids with stable resistance to diverse pathotypes of downy mildew in India.
\end{abstract}

Downy mildew, caused by Sclerospora graminicola (Sacc.) J. Schröt), is a serious disease of single-cross $F_{1}$ hybrid cultivars of pearl millet (Pennisetum glaucum (L.) R. Br.). Single-cross $F_{1}$ hybrid cultivars based on an $A_{1}$ cytoplasmic-nuclear malesterility (CMS) system have contributed significantly in increasing productivity of pearl millet in India $(2,7,18)$. Since the release of the first series of pearl millet $F_{1}$ hybrids in India during the late 1960s, downy mildew, hitherto known as a minor disease, became a disease of significant economic importance $(10,11,12,25)$. The first widely cultivated commercial hybrid HB 3, developed on Tift 23A, was released in 1968, and the first epidemic of downy mildew occurred in 1971, causing a severe grain yield loss $(12,15,16)$. Since then, a number of hybrids have succumbed to downy mildew and have been withdrawn from cultivation $(15,22)$. Although the $A_{1}$ cytoplasm of male-sterile lines (A-lines) has been shown not to be involved in susceptibility to downy mildew $(1,27)$, the genetic uniformity of single-cross $F_{1}$ hy-

Corresponding author: R. P. Thakur

E-mail: r.thakur@cgiar.org

Accepted for publication 16 February 2001.

Publication no. D-2001-0326-03R

(C) 2001 The American Phytopathological Society brids provides little barrier, if any, to the pathogen in rapidly adapting to the new cultivar and overcoming the host resistance compared with genetically heterogeneous open-pollinated varieties $(18,23)$. High harvest index, early maturity, and uniform crop stature of $\mathrm{F}_{1}$ hybrid cultivars have attracted farmers, and currently about $55 \%$ of the total 10 million ha under pearl millet cultivation in India is being grown with hybrid cultivars. During the past 20 years, private seed companies, in association with the Pearl Millet Improvement Program of International Crops Research Institute for the Semi-Arid Tropics (ICRISAT) and the Indian Council of Agricultural Research (ICAR) have played a significant role in extending hybrid cultivars to farmers. Today, more than 50 hybrids are being cultivated in India (18). The downy mildew pathogen has evolved rapidly to keep pace with changing cultivars. Evidence exists of evolution of several races or pathotypes specific to popular hybrid cultivars in India $(14,21,22,23)$. In our recent field surveys in states of Maharashtra, Rajasthan, and Gujarat, disease incidence was 80 to $100 \%$ on a few hybrids in some farmers' fields (23), accounting for a considerable yield loss. Results of the International Pearl Millet Downy Mildew Virulence Nursery (IPMDMVN) have provided further evidence for the existence of variable pathotypes within and between countries in Asia and Africa (9). Circumstantial evidence exists for the emergence of a new virulent pathotype specific to an $F_{1}$ hybrid cultivar when it has been grown consecutively for 3 to 4 years in the same fields.

ICRISAT has a major research focus on developing parental lines, especially diversifying the genetic base of A-lines, which are disseminated to public organizations and private seed companies for use in developing $F_{1}$ hybrid cultivars $(3,8)$. Such hybrids have wider adaptation and higher grain yield potential. Our objective in this study was to evaluate the recently developed A-lines and identify those having resistance to diverse pathotypes of $S$. graminicola that exist in India. Such resistant A-lines, in combination with resistant male parents, would lead to the development of $F_{1}$ hybrids that will have broadbased resistance against diverse pathotypes and hence will likely be more stable for downy mildew resistance.

\section{MATERIALS AND METHODS}

Male-sterile lines. Forty-six malesterile lines (A-lines) consisting of 42 test A-lines and four control A-lines (81A, 841A, 843A, and 852A) along with a commercial hybrid (MBH 110) and a highly susceptible inbred line (7042S) were included in this study (Table 1). All the A-lines carry $\mathrm{A}_{1}$ cytoplasm except ICMA 97555, which carries $\mathrm{A}_{4}$ cytoplasm (18). The maintainer lines (B-lines) of all these A-lines were developed at ICRISAT, Patancheru. A majority of these was bred by crossing two commercial B-lines (81B and 843B) bred during the early 1980s with a diverse range of improved germ plasm providing sources of genetic diversity and downy mildew resistance. Maintainers of three A-lines (863A, ICMA 88004, and ICMA 98222) were developed by inbreeding and direct selection in the Iniadi landrace germ plasm. Maintainers of some of the A-lines produced during the late 1980s from earlier selection programs (e.g., ICMB 88006, ICMB 89111, ICMB $88004)$ that became commercial during subsequent years were involved in the second round of crossing and pedigree breeding of B-lines. The set of A-lines included in this study represents the widest range of diversity in A-line collections anywhere in the world. Among the four Alines that were used as controls, $81 \mathrm{~A}$ is the first A-line developed at ICRISAT, Patancheru, and it has been among the most widely used A-lines for breeding commercial hybrids in India. 841A has 
shown high degrees of resistance to downy mildew across locations, $843 \mathrm{~A}$ is highly susceptible to most pathotypes, and 852A has shown differential reaction with specific susceptibility to the Mysore pathotype (21). Two additional entries that were included as controls in this study are an $\mathrm{F}_{1}$ hybrid (MBH 110) that has shown differential reaction with specific susceptibility to the Jalna pathotype and a universal susceptible line (7042S).

Pathotypes of $S$. graminicola. Four pathotypes of $S$. graminicola from Patancheru (Sg 153), Mysore (Sg 048), Dur-

Table 1. Parentage of pearl millet male-sterile lines evaluated for resistance to downy mildew using diverse Indian pathotypes of Sclerospora graminicola

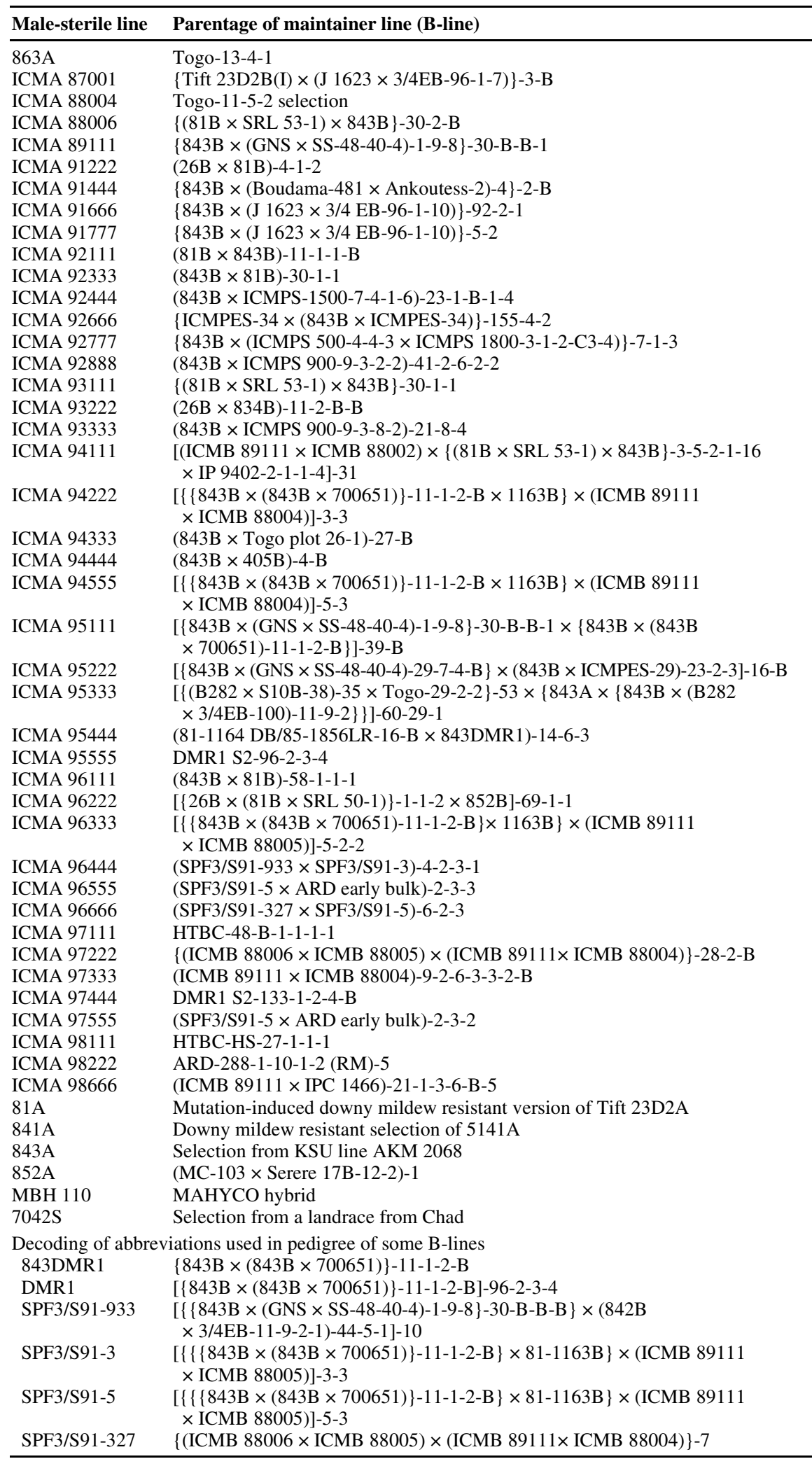

gapura (Sg 004), and Jalna (Sg 150) were maintained through asexual generations on pot-grown seedlings of different pearl millet lines in polyacrylic isolation chambers $(45 \times 45 \times 45 \mathrm{~cm})$ in a greenhouse at ICRISAT, Patancheru. Initial asexual inoculum of each pathotype isolate was established by growing pearl millet seedlings in pot soil infested by the respective oospores. Patancheru pathotype isolate was obtained from NHB 3, Durgapura pathotype from a susceptible local land race cultivar, Mysore pathotype from 852B, and Jalna pathotype from MBH 110. Patancheru and Durgapura pathotype isolates were maintained on 7042S, Mysore pathotype on $852 \mathrm{~B}$, and Jalna pathotype on MBH 110 through asexual generations for this study. The isolates from Durgapura and Patancheru were maintained on the universal susceptible line $7042 \mathrm{~S}$ because of nonavailability of pure seeds of the host lines from which these isolates were collected. These isolates were maintained for three to four asexual generations on seedlings in greenhouse isolation chambers before being used in this study.

Field evaluation. Seeds were sown in downy mildew nurseries at four locations in four states of India during the rainy season 1998. These were Patancheru $\left(17.53^{\circ} \mathrm{N}\right)$ in Andhra Pradesh, Mysore $\left(12.30^{\circ} \mathrm{N}\right)$ in Karnataka, Durgapura $\left(26.92^{\circ} \mathrm{N}\right)$ in Rajasthan, and Jalna $\left(19.83^{\circ} \mathrm{N}\right)$ in Maharashtra. Disease nurseries were created by incorporating diseased-leaf tissues containing oospores from the previous season's crop (16) supplemented with an infector-row system (26).

Disease pressure in nurseries was considered adequate for downy mildew evaluation when a susceptible control line had above $70 \%$ disease incidence. Each line was grown in 2 rows, $4 \mathrm{~m}$ long, in two or three replications in a randomized complete block design. Adequate fertilization and irrigation were provided to raise a good crop. Downy mildew was rated twice, at 30 and 60 days after seedling emergence, by counting the total plants and number of infected plants in each plot. The numbers of total plants per plot per replication were from 100 to 120 . Since there was an increase in the number of infected plants in some lines at 60 days compared with 30 days, the 60-day data were used for final analysis.

Greenhouse evaluation. Pearl millet seeds were sown in plastic pots $(15 \mathrm{~cm}$ diameter) filled with autoclaved potting mix of soil, sand, and farmyard manure $(2: 1: 1, \mathrm{vol} / \mathrm{vol} / \mathrm{vol})$. There were three replications, each with two pots and having a total of about 100 seedlings per entry per replication. Three days after sowing, all the emerged seedlings in each pot were counted. Seedlings that emerged after inoculation were disregarded. Sporangial suspensions $\left(1 \times 10^{6}\right.$ spores $\left.\mathrm{ml}^{-1}\right)$ were prepared from the pot-grown pearl millet 
seedlings infected with each isolate of the four pathotypes. Seedlings (one- to twoleaf stage) were spray-inoculated by a hand-held atomizer in the inoculation chamber and covered with polyethylene sheet to provide $>95 \%$ relative humidity necessary for infection. Inoculated seedlings were incubated in the dark at $20^{\circ} \mathrm{C}$. The pots were moved after $24 \mathrm{~h}$ to a greenhouse at $25 \pm 2{ }^{\circ} \mathrm{C}$ and arranged in a completely randomized block design. Downy mildew infection was recorded 2 weeks later by counting the number of diseased seedlings in each pot. Numbers of total and diseased seedlings were used to calculate the percent disease incidence. The experiment was repeated once with all four pathotypes.

Data analysis. Analysis of variance of downy mildew incidence data was done on both original and arcsine transformed scales using a fixed-effects model. Since the results of the analyses on both scales were similar, the mean incidence data were presented on the original scale. The analysis was done using GENSTAT statistical package (Rothamsted Experiment Station, Herpenden, Herts AL52JQ, UK). The field trial at each location was laid out in an RCBD, and observations on each plot were made at two times. Thus, the two time points were nested within each plot. Therefore, in order to compare and determine the effect of time (30- and 60-day data) on disease incidence, data from each location were analyzed as a split-plot trial with two time points as subplots. The time $\times$ line interaction effects were significant $(P<$ $0.05)$ at all locations. However, since the interactions were of non-crossover types, only the 60-day data were used for final analysis. Downy mildew incidence data sets both from field and greenhouse tests were subjected to an average linkage cluster analysis using Euclidian distance as dissimilarity measure to determine the association among the A-lines and classify them into major resistant and susceptible groups for strategic utilization in resistance breeding.

\section{RESULTS}

Resistance in field nurseries. Downy mildew incidences recorded at 30 and 60 days in four disease nurseries at four locations were similar for most pearl millet lines except at Mysore, where there was considerable increase in disease incidence in 21 of the 48 lines at 60 days (30-day data not provided). Analysis of variance for downy mildew incidence across four locations over two times indicated highly significant $(P<0.001)$ effects of location (pathotype), pearl millet lines, pathotype $\times$ line interaction, time point, pathotype $\times$ time, line $\times$ time, and pathotype $\times$ line $\times$ time $(P<0.004)$ (Table 2$)$.

Downy mildew pressure was high in all four tests in disease nurseries with 84 to $100 \%$ disease incidence on the susceptible control line 7042S (Table 3). We considered a line resistant if it had $\leq 10 \%$ disease incidence and moderately resistant to highly susceptible if it had 11 to $100 \%$ disease incidence. Of the 42 test A-lines, 38 were resistant at Patancheru, 32 at Durgapura, 25 at Mysore, and 22 at Jalna. There were eight lines (863A, ICMA 88004, -92111, -92777, -94333, -96666, -97111, and -98111) that had $\leq 10 \%$ disease incidence across all four locations. Among the A-lines used as controls, 841A was resistant and $843 \mathrm{~A}$ was susceptible at all four locations, while $81 \mathrm{~A}$ was resistant at Patancheru and Mysore but susceptible at Durgapura and Jalna. MBH 110, a popular $\mathrm{F}_{1}$ hybrid in Maharashtra until a few years ago, had high disease incidence $(81 \%)$ at Jalna, while it recorded low disease incidence (13\%) at Durgapura and remained resistant at Patancheru and Mysore and was identified as a differential host with high specific susceptibility to Jalna pathotype. Likewise, $852 \mathrm{~A}$, identified earlier as a differential host with high specific susceptibility to Mysore pathotype, recorded high disease at Mysore $(79 \%)$, had low disease incidence at Jalna (24\%) and Patancheru (13\%), and was resistant at Durgapura. Differential disease reactions across locations were evident in many test A-lines. For instance, ICMA 98666 was susceptible at Patancheru (20\% incidence) and Mysore (55\% incidence), but remained resistant at the other two locations. At Jalna, there were as many as 15 test Alines that had $>20 \%$ disease incidence, and seven of these had 44 to $76 \%$ incidence.

Resistance in greenhouse evaluation. Variability in downy mildew incidence due to genetic differences among A-lines, due to pathotype, and due to line $\times$ pathotype interaction were all highly significant $(P<$ 0.001) (Table 4). In both runs, the disease pressure with all four pathotypes was quite high, with 71 to $95 \%$ incidence on the susceptible control 7042S (Table 3). As in field tests, many lines were resistant ( $\leq 10 \%$ disease incidence) to each of the four pathotypes. Of the 42 test A-lines, 33 were resistant to the Patancheru pathotype (Sg 153), 29 to the Mysore pathotype (Sg 048), 28 to the Durgapura pathotype (Sg

Table 2. Analysis of variance for downy mildew incidence of 48 pearl millet lines at two times (30 and 60 days) after emergence under field conditions

\begin{tabular}{lrl}
\hline Source of variation & df & Mean squares \\
\hline Location (pathotype) & 3 & $11549.48^{*} * *(9254.48)^{* * * *}$ \\
Rep/location & 7 & $702.17(474.69)$ \\
Line & 47 & $4964.87 * * *\left(3272.677^{* * * *}\right.$ \\
Pathotype $\times$ line & 141 & $1398.21^{* * *}(956.30)^{* * * *}$ \\
Error 1 & 329 & $306.91(225.68)$ \\
Time & 1 & $3065.10 * * *(3291.74) * * *$ \\
Pathotype $\times$ time & 3 & $428.04 * * *(270.02)^{* * * *}$ \\
Line $\times$ time & 47 & $92.67 * * *(63.28)^{* * *}$ \\
Pathotype $\times$ line $\times$ time & 141 & $37.06 * *(27.80)^{* *}$ \\
Error 2 & 336 & $25.55(20.02)$ \\
\hline
\end{tabular}

a Values in parentheses are based on arcsine-transformed data. $* *$ and $* * *=$ significant at $P<0.01$ and $P<0.001$, respectively.
004), and 15 to the Jalna pathotype ( $\mathrm{Sg}$ 150). Again, differential reaction across pathotypes was evident in many lines. For instance, there were 9, 7, and 5 test A-lines that had $>20 \%$ downy mildew incidence against each of the Patancheru, Durgapura, and Mysore pathotypes, respectively. More than $40 \%$ incidence was recorded in six of these A-lines against the Patancheru pathotype, in one A-line against the Durgapura pathotype and in two A-lines against the Mysore pathotype. Against the Jalna pathotype, there were 20 test A-lines that had $>20 \%$ disease incidence, with 12 of these having $\geq 40 \%$ incidence.

Several A-lines provided differential reactions to the four pathotypes. Twelve test A-lines (863A, ICMA 88004, -88006, -92777, $-94333,-95444,-95555,-96666,-97444$, -97555, -98111, and -98222) recorded $\leq 10 \%$ disease incidence against all four pathotypes. As in field tests, $841 \mathrm{~A}$ was resistant to all four pathotypes, while $81 \mathrm{~A}$ and $843 \mathrm{~A}$ were susceptible to highly susceptible to different pathotypes. Again, MBH 110 remained resistant to all pathotypes, except to the Jalna pathotype. Downy mildew resistance of seven of these A-lines (863A, ICMA 88004, -92777, $-94333,-96666,-98111,-98222)$ out of the nine identified in the field test was confirmed in the greenhouse tests.

Resistance in both field and greenhouse evaluations. Using the average linkage cluster analysis for downy mildew incidence data from both field and greenhouse tests, the 48 lines were classified into four distinct groups (Fig. 1). These may be considered resistant (9 lines, including 841A), moderately resistant (10 lines), susceptible (12 lines, including 852A), and highly susceptible (17 lines, including $\mathrm{MBH} 110,81 \mathrm{~A}$, 843A, and 7042S) groups. ICMA 96333, although classified into the resistant group by cluster analysis, had 16 and $11 \%$ incidence in the field nursery at Mysore and to Jalna pathotype in the greenhouse, respectively (Table 3).

\section{DISCUSSION}

Evaluation of recently developed genetically diverse and agronomically elite pearl millet A-lines against diverse Indian patho- 
types of $S$. graminicola has provided lines with resistance to multiple pathotypes both under multilocation field and greenhouse environments. Genetic diversity for downy mildew resistance in A-lines was evident from variable incidence levels to four pathotypes, both in field nurseries and in greenhouse tests. Disease incidence in Alines was quite variable, but the incidence levels on the susceptible control 7042S indicated high and adequate disease pressure in all tests. There was also variation in disease incidence between field nurseries at different locations, and those between field and greenhouse tests against a particular pathotype. In addition to genetic differences in host lines, there are several weather factors that influence downy mildew infection and symptom expression under field conditions $(6,11,15,16)$. For instance, increase in disease incidence from 30- to 60-day recording in 20 of the 48 lines in the disease nursery at Mysore could be attributed to the prevalence of more conducive environments at a later part of plant growth than at the seedling stage. Since downy mildew infection in pearl millet is systemic, oftentimes symp- toms and sporulation can be suppressed under unfavorable weather conditions.

The difference in results between field and greenhouse evaluations against the same pathotype isolates could be attributed to several variable factors operating in the fields. Environments and inoculum are more variable in field nurseries than in the greenhouse. In the field, infection to seedlings occurs both by soilborne oospores (primary infection) and airborne zoospores (secondary infection from infector rows), while in the greenhouse it is only due to zoospores. The fact that field resistance of

Table 3. Downy mildew reactions of pearl millet male-sterile lines (A-lines) against four pathotypes of Sclerospora graminicola under field (FD) and greenhouse $(\mathrm{GH})$ conditions

\begin{tabular}{|c|c|c|c|c|c|c|c|c|}
\hline \multirow[b]{3}{*}{ Designation } & \multicolumn{8}{|c|}{ Downy mildew incidence (\%) } \\
\hline & \multicolumn{2}{|c|}{ Patancheru } & \multicolumn{2}{|c|}{ Mysore } & \multicolumn{2}{|c|}{ Durgapura } & \multicolumn{2}{|c|}{ Jalna } \\
\hline & FD $^{\mathbf{a}}$ & $\mathbf{G H}^{\mathbf{b}}$ & FD & GH & FD & GH & FD & GH \\
\hline $863 \mathrm{~A}$ & 0 & 0 & 8 & 2 & 0 & 0 & 0 & 0 \\
\hline ICMA 87001 & 2 & 4 & 12 & 1 & 26 & 11 & 2 & 57 \\
\hline ICMA 88004 & 0 & 0 & 6 & 1 & 1 & 3 & 0 & 0 \\
\hline ICMA 88006 & 9 & 0 & 7 & 1 & 8 & 7 & 11 & 7 \\
\hline ICMA 89111 & 4 & 6 & 9 & 5 & 43 & 26 & 6 & 15 \\
\hline ICMA 91222 & 7 & 0 & 17 & 6 & 1 & 24 & 29 & 77 \\
\hline ICMA 91444 & 10 & 3 & 32 & 6 & 25 & 4 & 44 & 39 \\
\hline ICMA 91666 & 3 & 0 & 8 & 4 & 58 & 2 & 13 & 52 \\
\hline ICMA 91777 & 7 & 2 & 13 & 2 & 16 & 5 & 31 & 83 \\
\hline ICMA 92111 & 0 & 0 & 6 & 6 & 0 & 9 & 3 & 25 \\
\hline ICMA 92333 & 8 & 59 & 48 & 12 & 8 & 28 & 23 & 32 \\
\hline ICMA 92444 & 12 & 26 & 21 & 20 & 1 & 29 & 5 & 15 \\
\hline ICMA 92666 & 3 & 77 & 14 & 61 & 9 & 66 & 25 & 57 \\
\hline ICMA 92777 & 0 & 4 & 7 & 3 & 3 & 0 & 4 & 0 \\
\hline ICMA 92888 & 2 & 34 & 59 & 28 & 0 & 19 & 3 & 50 \\
\hline ICMA 93111 & 3 & 0 & 11 & 4 & 4 & 5 & 23 & 14 \\
\hline ICMA 93222 & 4 & 44 & 30 & 29 & 1 & 20 & 63 & 49 \\
\hline ICMA 93333 & 0 & 30 & 10 & 10 & 0 & 15 & 35 & 10 \\
\hline ICMA 94111 & 4 & 1 & 9 & 13 & 44 & 17 & 10 & 28 \\
\hline ICMA 94222 & 8 & 0 & 14 & 15 & 0 & 5 & 13 & 87 \\
\hline ICMA 94333 & 4 & 1 & 10 & 0 & 2 & 1 & 0 & 0 \\
\hline ICMA 94444 & 0 & 0 & 4 & 7 & 68 & 4 & 0 & 16 \\
\hline ICMA 94555 & 8 & 0 & 9 & 1 & 20 & 6 & 9 & 40 \\
\hline ICMA 95111 & 5 & 0 & 11 & 1 & 3 & 2 & 4 & 33 \\
\hline ICMA 95222 & 4 & 0 & 8 & 2 & 1 & 4 & 59 & 66 \\
\hline ICMA 95333 & 8 & 43 & 10 & 46 & 1 & 34 & 76 & 39 \\
\hline ICMA 95444 & 0 & 4 & 10 & 5 & 0 & 6 & 76 & 6 \\
\hline ICMA 95555 & 18 & 1 & 79 & 2 & 7 & $<1$ & 38 & 3 \\
\hline ICMA 96111 & 8 & 10 & 9 & 13 & 4 & 6 & 56 & 22 \\
\hline ICMA 96222 & 0 & 1 & 14 & 12 & 2 & 2 & 3 & 35 \\
\hline ICMA 96333 & 3 & 0 & 16 & 0 & 0 & 3 & 0 & 11 \\
\hline ICMA 96444 & 2 & 2 & 10 & 10 & 8 & 2 & 47 & 79 \\
\hline ICMA 96555 & 7 & 0 & 9 & 7 & 16 & 5 & 15 & 72 \\
\hline ICMA 96666 & 0 & 6 & 10 & 3 & 0 & 2 & 3 & 7 \\
\hline ICMA 97111 & 5 & 88 & 10 & 19 & 3 & 20 & 9 & 10 \\
\hline ICMA 97222 & 25 & 44 & 12 & 23 & 5 & 33 & 17 & 10 \\
\hline ICMA 97333 & 3 & 0 & 8 & 4 & 12 & 3 & 7 & 18 \\
\hline ICMA 97444 & 5 & 0 & 55 & 1 & 6 & 0 & 0 & 3 \\
\hline ICMA 97555 & 4 & 0 & 7 & 1 & 7 & $<1$ & 24 & 10 \\
\hline ICMA 98111 & 7 & 0 & 8 & 1 & 1 & $<1$ & 4 & 0 \\
\hline ICMA 98222 & 4 & 0 & 10 & 0 & 1 & $<1$ & 0 & 0 \\
\hline ICMA 98666 & 20 & 0 & 55 & 12 & 0 & 11 & 3 & 19 \\
\hline \multicolumn{9}{|l|}{ Controls } \\
\hline $81 \mathrm{~A}$ & 2 & 25 & 10 & 33 & 14 & 32 & 61 & 17 \\
\hline $841 \mathrm{~A}$ & 5 & 0 & 8 & 2 & 0 & 9 & 3 & 4 \\
\hline $843 \mathrm{~A}$ & 66 & 94 & 82 & 45 & 39 & 24 & 46 & 43 \\
\hline $852 \mathrm{~A}$ & 13 & 0 & 79 & 18 & 8 & 4 & 24 & 54 \\
\hline MBH110 (hybrid) & 0 & 0 & 10 & $<1$ & 13 & $<1$ & 81 & 81 \\
\hline $7042 \mathrm{~S}$ (line) & 100 & 95 & 93 & 91 & 96 & 91 & 84 & 70 \\
\hline SE & \pm 5.7 & \pm 1.6 & \pm 6.9 & \pm 1.8 & \pm 7.4 & \pm 2.1 & \pm 8.4 & \pm 2.6 \\
\hline CV (\%) & 13.3 & 2.0 & 20.1 & 6.3 & 3.0 & 3.2 & 11.2 & 2.8 \\
\hline
\end{tabular}

a Mean of three replications, except Patancheru (two replications) with two rows per plot per replication and 100 to 120 plants per plot.

${ }^{\mathrm{b}}$ Mean of two runs with three replications per run and 60 to 80 seedlings per replication per line. 
eight of the nine tested A-lines was confirmed in two greenhouse tests indicates the value, effectiveness, and usefulness of the greenhouse evaluation.

Greenhouse evaluation of A-lines against the four pathotypes provided comparatively more uniform results (with low coefficient of variations) in the two runs than did the field evaluation. Among the three sources of variation (line, pathotype, and line $\times$ pathotype), the largest proportion of variability for downy mildew incidence was accounted for by lines, followed by line $\times$ pathotype interaction and pathotypes, both in field and greenhouse tests (Tables 2 and 4). The largest number of Alines (38 out of 42) among the test entries was resistant in the field nursery at Patancheru and the lowest number (22) at Jalna, with Durgapura and Mysore falling between the two, in that order. This difference in the number of resistant lines among the locations might arise either from the environmental differences or from differences among the dominant genotypes in the pathogen populations, or from a combination of both factors.

Greenhouse evaluation of these A-lines with pathotypes from the same four locations also showed a similar pattern, with the largest number of test A-lines (33) being resistant to Patancheru pathotype and the lowest number (15) being resistant to Jalna pathotype, confirming that Jalna pathotype is more virulent than Durgapura and Mysore pathotypes. However, it cannot be claimed that these three pathotypes are necessarily more virulent than the Patancheru pathotype. The largest number of Alines resistant to Patancheru pathotype may simply be for the reason that these A-lines have been bred for their resistance using the Patancheru disease nursery over several seasons. Earlier studies $(13,23)$ have shown that the four pathotypes used in this study are quite diverse for their virulence

Table 4. Analysis of variance for downy mildew incidence of 48 pearl millet lines against four pathotypes in two runs in a greenhouse experiment

\begin{tabular}{lrl}
\hline Source of variation & df & Mean square $^{\mathbf{a}}$ \\
\hline Replication & 2 & $5.79(5.03)$ \\
Run & 1 & $0.04(0.41)$ \\
Pathotype & 3 & $25958.20^{* * *}(19437.62)^{* * *}$ \\
Line & 47 & $6273.20^{* * *}(4314.52)^{* * *}$ \\
Run $\times$ pathotype & 3 & $79.51(97.40)$ \\
Run $\times$ line & 47 & $8.99(14.62)$ \\
Pathotype $\times$ line & 141 & $1547.88 * * *(935.84)^{* * *}$ \\
Run $\times$ pathotype $\times$ line & 141 & $8.46(16.57)$ \\
Error & 766 & $25.65(23.04)$ \\
\hline
\end{tabular}

a Values inside parentheses are for arcsine-transformed data. $* * *=$ significant at $P<0.001$.

and genetic makeup, and that these are present in the major pearl millet growing areas of India. Yet more than $40 \%$ of the Alines bred for resistance at Patancheru were found to be resistant to a pathotype from another location. This could result from chance fixation of genes responsible for resistance against pathotypes from other locations; or a Patancheru pathotype may consist of a low frequency of those pathogen genotypes dominant at other locations, permitting simultaneous selection for resistance to multiple pathotypes. Results of a serial passage study with Patancheru pathotype on several differential host genotypes showed that this pathogen population was a heterogeneous mixture of several genotypes that evolved during serial passage into divergent subpopulations with differential pathogenic reaction (24).

Inbred line 843B is maintainer of 843A, which is the best source of earliness combined with large seed size in a dwarf and agronomically elite background (18). Thus, in A-line breeding at ICRISAT, Patancheru, extensive use of 843B has been made in crosses, with the result that it is one of the parents in almost all the A-lines included in this study. However, 843B is highly susceptible to downy mildew in all the pearl millet growing areas of India. Clearly, then, resistance in the test A-lines came from the other parents used in crosses, almost all of which are of western African origin. It is well known that pearl millet lines that are resistant in western and central Africa (WCA) are mostly resistant in India, but not vice versa $(4,5,15,19)$. Similarly, resistance in

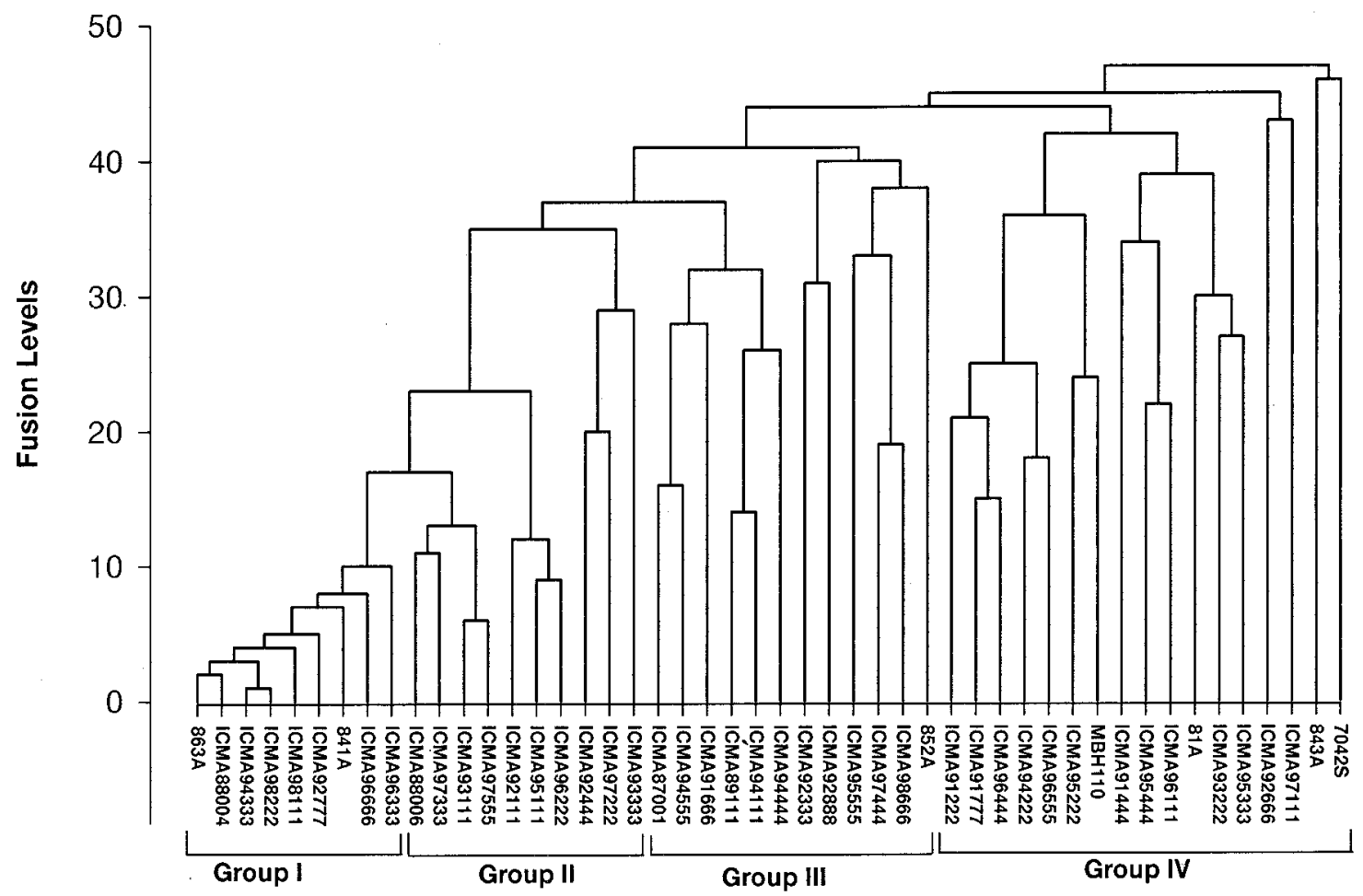

Fig. 1. Classification of 48 pearl millet lines based on average linkage cluster analysis using Euclidian distance of downy mildew incidence (\%) caused by Sclerospora graminicola in disease nurseries at four locations and four pathotypes in greenhouse experiments: group I = resistant, group II = moderately resistant, group III = susceptible, and group IV = highly susceptible . 
line ICMA 88004 seems to have come from the parental line from Togo 11-5 that has shown resistance to downy mildew in field tests at Patancheru (17), and resistance in ICMA 92777 is from either or both of the smut and downy mildew resistant parental lines ICMPS 500-4-4-3 and ICMPS 1800, which have been derived from crosses involving lines from WCA (20). Identification of eight A-lines (863A, ICMA 88004, -92777, -94333, -96666, -98111, -98222, and 841A), which were found to be resistant to all four pathotypes in both field and greenhouse evaluations, provides opportunity for their direct use in breeding hybrid cultivars with resistance to multiple pathotypes of $S$. graminicola. Use of a resistant male parent that can combine well with these A-lines for high grain yield and increased downy mildew resistance would provide durability and wider adaptability of hybrid cultivars in India. These lines also provide a genetic resource in improved genetic background for their further utilization in a crossing program for breeding new A-lines with stable downy mildew resistance. Further, the maintainer counterpart of these A-lines can also be used to develop a downy mildew resistant maintainer composite for eventual use in breeding new A-lines with stable downy mildew resistance. However, since three of these test A-lines are direct derivatives from Iniadi germ plasm and two other A-lines also involve Iniadi germ plasm in their parentage, such a composite will have a narrow genetic base for agronomic traits, although high resistance to various pathotypes of downy mildew. Therefore, a better strategy would be to include maintainers of $10 \mathrm{~A}$ lines from group II (moderately resistant) to develop a composite with a broader genetic base for agronomic traits.

\section{ACKNOWLEDGMENTS}

We thank Dr. S. Chandra for his advice on data analysis and Mr. V. Pappaiah for his help with developing the dendrogram.

\section{LITERATURE CITED}

1. Anand Kumar, K., Jain, R. P., and Singh, S. D. 1983. Downy mildew reactions of pearl millet lines with and without cytoplasmic male sterility. Plant Dis. 67:663-665.

2. Andrews, D. J. 1987. Breeding pearl millet grain hybrids. Pages 83-109 in: Hybrid seed production of selected cereal oil and vegetable crops. W. P. Feistritzer and A. F. Kelly, eds. FAO Plant Production and Protection Paper 82. Food and Agriculture Organization of the United Nations, Rome, Italy.

3. Andrews, D. J., King, S. B., Witcombe, J. R., Singh, S. D., Rai, K. N., Thakur, R. P., Talukdar, B. S., Chavan, S. B., and Singh, P. 1985. Breeding for disease resistance and yield in pearl millet. Field Crops Res.11:241-258.

4. Ball, S. L. 1983. Pathogenic variability of downy mildew (Sclerospora graminicola) on pearl millet. 1. Host cultivar reactions to infection by different pathogen isolates. Ann. Appl. Biol. 102:257-264.

5. Ball, S. L., Pike, D. J., and Burridge, C. Y. 1986. Characterisation of populations of Sclerospora graminicola. Ann. Appl. Biol. 108:519-526.

6. Bhat, S. S. 1973. Investigations on the biology and control of Sclerospora graminicola on bajra, Ph.D. thesis. Department of Post Graduate Studies and Research in Botany, University of Mysore, Mysore, India.

7. Dave, H. R. 1987. Pearl millet hybrids. Pages 121-126 in: Proc. Int. Pearl Millet Workshop. J. R. Witcombe and S. R. Beckerman, eds. ICRISAT, Patancheru, India.

8. Hash, C. T. 1997. Research on downy mildew of pearl millet. Pages 121-128 in: Integrating Research Evaluation Efforts: Proceedings of an International Workshop 14-16 Dec. 1994. M. C. S. Bantilan and P. K. Joshi, eds. ICRISAT, Patancheru, India.

9. International Pearl Millet Downy Mildew Virulence Nursery (IPMDMVN)- A Summary Report 1992-1998. ICRISAT, Patancheru, India.

10. Nene, Y. L., and Singh, S. D. 1976. Downy mildew and ergot of pearl millet. PANS 22:366-385.

11. Safeeulla, K. M. 1976. Biology and control of the downy mildew of pearl millet, sorghum and fingermillet. Wesley Press, Mysore, India.

12. Safeeulla, K. M. 1977. Genetic vulnerability: The basis of recent epidemics in India. Ann. N.Y. Acad. Sci. 287:72-85

13. Sastry, J. G., Ramakrishna, W., Sivaramkrishnan, S., Thakur, R. P., Gupta, V. S., and Ranjekar, P. K. 1995. DNA fingerprinting detects genetic variability in the pearl millet downy mildew pathogen (Sclerospora graminicola). Theor. Appl. Genet. 91:856-861.

14. Shetty, H. S., and Ahmad, R. 1981. Physiologic specialization in Sclerospora gramini- cola. Indian Phytopathol. 34:307-309.

15. Singh, S. D. 1995. Downy mildew of pearl millet. Plant Dis. 79:545-550.

16. Singh, S. D., King, S. B., and Werder, J. 1993. Downy mildew disease of pearl millet. Inf. Bull. 37. ICRISAT, Patancheru, India.

17. Singh, S. D., Wilson, J. P., Navi, S. S., Talukdar, B. S., Hess, D. E., and Reddy, K. N 1997. Screening technique and sources of resistance to downy mildew and rust in pearl millet. Inf. Bull. 48. ICRISAT, Patancheru, India.

18. Talukdar, B. S., Khairwal, I. S., and Singh, R. 1999. Hybrid breeding. Pages 269-301 in: Pearl Millet Breeding. I. S. Khairwal, K. N Rai, D. J. Andrews, and G. Harynarayana, eds. Oxford \& IBH Publishing Co., New Delhi, India.

19. Thakur, R. P. 1995. Status of international sorghum anthracnose and pearl millet downy mildew virulence nurseries. Pages 75-92 in: Disease Analysis through Genetics and Biotechnology: Interdisciplinary Bridges to Improve Sorghum and Millet Crops. J. F. Leslie and R. A. Frederiksen, eds. Iowa State University, Ames.

20. Thakur, R. P., King, S. B., Rai, K. N., and Rao, V. P. 1992. Identification and utilization of smut resistance in pearl millet. Res. Bull. 16. ICRISAT, Patancheru, India.

21. Thakur, R. P., and Rao, V. P. 1997. Variation in virulence and aggressiveness among pathotypes of Sclerospora graminicola on pearl millet. Indian Phytopathol. 50:41-47.

22. Thakur, R. P., Rao, V. P., and Hash, C. T. 1998. A highly virulent pathotype of Sclerospora graminicola from Jodhpur, Rajasthan, India. Int. Sorghum Millets Newsl. 39:140142.

23. Thakur, R. P., Rao, V. P., Sastry, J. G., Sivaramakrishnan, S., Amruthesh, K. N., and Barbind, L. D. 1999. Evidence for a new virlent pathotype of Sclerospora graminicola on pearl millet. J. Mycol. Plant Pathol. 29:61-69.

24. Thakur, R. P., Shetty, K. G., and King, S. B. 1992. Selection for host-specific virulence in asexual populations of Sclerospora graminicola. Plant Pathol. 41:626-632.

25. Williams, R. J. 1984. Downy mildews of tropical cereals. Adv. Plant Pathol. 2:1-103.

26. Williams, R. J., Singh, S. D., and Pawar, M N. 1981. An improved field screening technique for downy mildew resistance in pearl millet. Plant Dis. 65:239-241.

27. Yadav, O. P., Manga, V. K., and Gupta, G. K 1993. Influence of A1 cytoplasmic substitution on the downy mildew incidence of pearl millet. Theor. Appl. Genet. 87:558-560. 